\title{
Erratum to: Foreign direct investment in the Dominican Republic: consequences and recommendations for sustainable growth
}

\section{Harri Ramcharran ${ }^{1}$}

Published online: 21 June 2016

(C) Springer Science+Business Media New York 2016

\section{Erratum to: J Econ Finan}

DOI 10.1007/s12197-016-9361-y

The original version of this paper unfortunately contained mistakes. These mistakes are as follows:

Equation 1 is incorrect and the corrected equation is shown below.

$$
\mathrm{Y}=\mathrm{e}^{\mathrm{a}_{0}} \mathrm{~K}^{\mathrm{a}_{1}+\mathrm{a}_{3}}{ }^{1 n L} \mathrm{~L}^{\mathrm{a}_{2}}
$$

- In Section 5.1, Free trade zone area, $\hat{R}^{2}$ is missing in the $3^{\text {rd }}$ sentence of the paragraph directly below the displayed equation. The affected sentence should read An adjusted $\hat{R}^{2}$ of 0.90 indicates a high explanatory power of the model, while the Durbin-Watson (DW) statistic of 1.62 indicates no evidence of first order autocorrelation.

- In Section 5.2, Rest of the economy, $\hat{R}^{2}$ is missing in the $3^{\text {rd }}$ sentence of the paragraph directly below the displayed equation. The affected sentence should read An adjusted $\hat{R}^{2}$ of 0.96 , indicating a high explanatory power of the model, and the Durbin-Watson (DW) statistic of 1.60 indicating no evidence of first order autocorrelation.

The online version of the original article can be found at http://dx.doi.org/10.1007/s12197-016-9361-y.

Harri Ramcharran

ramchar@uakron.edu

1 Department of Finance, College of Business, University of Akron, Akron, OH 44325, USA 